\title{
1 The Nagoya Protocol could backfire on the Global South
}

2

$6{ }^{1}$ Ethics Research Institute (ERI), University of Zurich, Zollikerstrasse 117, CH-8008

7 Zurich

82 Department of Geography, University of Zurich, Winterthurerstrasse 190, CH-8057

9 Zurich, Switzerland

$10{ }^{3}$ Department of Evolutionary Biology and Environmental Studies,

11 University of Zurich, Winterthurerstrasse 190, CH-8057 Zurich, Switzerland

$12{ }^{4}$ Eawag, Swiss Federal Institute of Aquatic Science and Technology, Department of

13 Aquatic Ecology, Ueberlandstrasse 133, CH-8600 Duebendorf, Switzerland 14

$15 \quad{ }^{5}$ Corresponding author: deplazes@ethik.uzh.ch

16

17

18

19

20

21 This article was published in Nature Ecology \& Evolution 2, 917-919 (2018)

22

DOI: https://doi.org/10.1038/s41559-018-0561-z 
 \\ The Nagoya Protocol could backfire on the Global South}

Regulations designed to prevent global inequalities in the use of genetic resources apply to both commercial and non-commercial research. Conflating the two may have unintended consequences for collaboration between the Global North and biodiverse countries in the Global South, which may promote global injustice rather than mitigate it.

Research in ecology and evolution is essential to achieve effective environmental policy, for example in relation to biodiversity conservation strategies. At the same time, policy decisions directly influence research activities and outcomes in ecology and evolution. This bidirectional interaction takes place in a context involving societal, economic, cultural and other aspects. The Nagoya Protocol (NP) to the Convention of Biological Diversity (CBD) is an example of an international agreement established in such an interacting context. The NP aims at ensuring fair and equitable sharing of benefits originating from the utilization of genetic resources and thus addresses the unbalanced situation where users of genetic resources are typically located in industrialised countries in the Global North, while most biodiversity-rich provider countries are located in the Global South, often representing low-income countries. Regulations on Access to Genetic Resources and the Fair and Equitable Sharing of Benefits Arising from their Utilization (ABS), as outlined in the NP, were designed to reduce global inequalities originating from the commercial utilization of genetic resources. However, these regulations are also applied to non-commercial research, potentially creating unwanted side-effects.

This comment addresses the complex interplay between scientific, economic, social, and ethical factors from the point of view of an interdisciplinary group of researchers studying the impact of global change drivers on biodiversity and ecosystem services. We initiated collaborations involving exchange of genetic resources with researchers in various provider countries, and experienced that the NP has a strong effect on non-commercial research as noted previously ${ }^{1-6}$. We are concerned that consequences of the NP can have further effects that go far beyond the administrative burden for researchers in user countries. We argue that provider countries will also be affected, because the NP unintentionally impedes collaboration between researchers in provider and user countries. Consequently, researchers from many provider countries, typically located in the Global South, will have increasing difficulties to connect to 
58

59

60

61

62

63

64

65

66

67

68

69

70

71

72

73

74

75

76

researchers in the user countries, usually located in the Global North. Such an impeding effect of the NP would not only be worrisome for scientific researchers but also from an ethics perspective because it increases global injustice between academic institutions. In addition to being unethical it also contradicts the purpose of the NP to increase global fairness and equitability.

\section{Motivation behind the NP}

A strong request for a binding agreement on ABS for genetic resources was particularly put forward by biodiversity-rich countries in the Global South. Even before this request was finally granted with the adoption of the NP (Box 1), various countries had already ABS regulations and legislation in place ${ }^{5}$. However, in cases where genetic resources were illegally accessed and removed from their territory, provider countries were not able to prosecute illegal beneficiaries. Therefore, these countries largely voted in favour of implementing a binding protocol ${ }^{7}$.

\section{The NP may impede North-South research collaboration}

During negotiation and implementation of the NP, different authors commented on the fact that the NP - although drafted with a focus on commercial utilization of genetic resources - strongly affects non-commercial research ${ }^{1-6}$. In only one of the NP's 36 articles - namely article $8 \mathrm{a}-$ it is mentioned that a distinction between noncommercial and commercial research should be made. The rationale to introduce this distinction in article $8 \mathrm{a}$ is to promote and encourage research that contributes to the conservation and sustainable use of biological diversity. However, the list of suggested non-monetary benefits in the NP Annex clearly shows that non-commercial research is just as much a target of this protocol as commercial use. Whether - and to what extent - researchers working with genetic resources across countries need to enter ABS negotiations depends on the regulatory framework in the provider country. Some countries, such as Brazil or Australia, have introduced simplified measures for noncommercial research in their ABS legislation ${ }^{8,9}$.

Some authors expected that the NP will encourage collaboration between research groups in user and provider countries of genetic resources ${ }^{7,10}$. However, based on experiences and observations in our scientific environment (Box 2), we argue that the contrary is the case, and that the NP is likely to cause unintended negative effects and to impede such collaborations. International collaborative research is essential in 
global change and biodiversity sciences. We consider it a question of good scientific practice that the needs of all collaboration partners are taken into account, including particular interests of less affluent provider countries ${ }^{11}$. Therefore, sharing "nonmonetary benefits" (NP, Annex) should be part of scientific routine, even when no genetic resources are involved.

There is a long tradition of exchange in our scientific community between researchers in provider and user countries. In such situations we perceive a rigorous implementation of strict ABS regulations as being more hindering than promoting research collaboration. We argue that it is of key importance to pay more attention to the consequences of the NP for non-commercial research, not only to protect important scientific projects as argued by others ${ }^{1-6}$, but also for reasons of global justice. We propose specific suggestions on how different players can contribute to prevent that the NP backfires on the Global South (Box 3).

The difficulties for collaboration introduced by the NP cannot deny the responsibility of researchers to enter mutually fair scientific exchange - neither in user nor in provider countries. Equitable research on genetic resources involves scientists in provider as well as user countries. For reasons of fairness there should be more benefitsharing collaborations between more and less affluent countries, independent of whether genetic resources are exchanged or not, and independent of the direction of exchange. However, besides their moral responsibilities scientists also have economic and time constraints. The risk of additional costs, delays and uncertainties associated with formalities related to the NP are key factors researchers will include in their decision making process when considering scientific collaborations ${ }^{12}$.

\section{Global injustice as a consequence of the NP?}

Most utilization of genetic resources concerns non-commercial rather than commercial research as, for instance, suggested by published numbers of research permits issued in Australia and Brazil ${ }^{5,8}$. Non-monetary benefits resulting from such non-commercial research play a central role in ABS as requested by the NP. Based on our experience and observation, we are concerned that the NP could lead to hesitative attitudes and a reduction of collaboration rather than to an increase between users and providers of genetic resources, which is ethically most alarming, because it would reduce the sharing of scientific benefits between user and provider countries and thus increase global injustice. These consequences would be highly paradox, as they would be 
caused by legislation developed to increase fairness and equitability when using genetic resources.

The inequality between the Global North and South, with poverty, authoritarian regimes, war, and other humanitarian catastrophes accumulating in the South, is one of the biggest ethical challenges of our times ${ }^{13,14}$. We expect academic research acting simultaneously as an indicator for this inequality as well as a driver towards it. On the one hand, more academic research is a positive indicator for the well-being of a country, because a well-functioning research system depends on the availability of financial resources, political stability, and freedom of opinion and expression. On the other hand, academic research likely is a driver towards high quality of life because it brings innovation and technological progress, as well as an understanding of natural, political and cultural development. This goes along with more education and opportunities for citizens as well as more power and influence of the respective country. It is the responsibility of all involved players, including academics and policy makers, to prevent that the implementation of the NP leads to a further increase in global inequality. We therefore strongly propose mitigation efforts by acting along our proposed measures (see Box 3).

\section{Acknowledgments}

We thank Cornelia Schauz, Sylvia I. Martinez and two anonymous reviewers for comments on the manuscript. This work was supported by the UZH Research Priority Program on 'Global Change and Biodiversity'. FA was also supported by the Swiss National Science Foundation (grant no. PP00P3_150698).

\section{References}

$1 \quad$ Cock, M. Nature 467, 369, doi:10.1038/467369a (2010).

2 Comizzoli, P. \& Holt, W. V. Reprod Fertil Dev, doi:10.1071/RD15429 (2016).

3 Jinnah, S. \& Jungcurt, S. Science 323, 464-465, doi:10.1126/science.1167234 (2009).

4 Martinez, S. I. \& Biber-Klemm, S. Current Opinion in Environmental Sustainability 2, 1-7, doi:10.1016/j.cosust.2010.03.004 (2010).

$5 \quad$ Schindel, D. E. Nature 467, 779-781, doi:10.1038/467779a (2010).

6 Schindel, D. E. \& du Plessis, P. Nature 515, 37, doi:10.1038/515037a (2014).

7 Medaglia, J. C. in International Environmental Law and the Global South (eds Shawkat Alam, Sumudu Atapattu, Carmen G. Gonzalez, \& Jona Razzaque) 192213 (Cambridge University Press, 2015).

8 Gross, T. ABS Capacity Development Initiative, abailable at: http://www.absinitiative.info/fileadmin/media/Knowledge_Center/Pulications/ABS_Dialogue_042 
164

165

166

167

168

169

170

171

172

173

174

175

176

177

178

179

180

181

182

183

184

185

186
014/National_study_on_ABS_implementation_in_Brazil_20140716.pdf(accessed March 2018) (2014).

9 IEEP (Institute for European Environmental Policy). availabla at: http://ec.europa.eu/environment/nature/biodiversity/international/abs/pdf/ABS \%20FINAL\%20REPORT\%20-\%20Annexes.pdf (accessed March 2018) (2012).

10 Dedeurwaerdere, T., Melindi-Ghidi, P. \& Arianna, B. Environmental Science \& Policy 55, 1-10, doi:10.1016/j.envsci.2015.08.006 (2016).

11 KFPE, (Swiss Commission for Research Partnerships with Developing Countries). (available at: http://www.naturalsciences.ch/service/publications/9505-aguide-for-transboundary-research-partnerships-2nd-edition---2014 (accessed January 2018) (2014).

12 Biber-Klemm, S. \& Martinez, S. I. in Research and Development on genetic resources - public domain approaches in implementing the Nagoya Protocol (eds Chege Kamau Evanson, Winter Gerd, \& Stoll Peter-Tobias) 175-180 (Routledge, 2015).

13 Pogge, T. in World Poverty and Human Rights (ed Thomas Pogge) 202-221 (Polity Press, 2002).

14 Bleisch, B. \& Schaber, P. Weltarmut und Ethik. (Mentis, 2007).

15 Nijar, G. S., Louafi, S. \& Welch, E. W. International Environmental Agreements: Politics, Law and Economics, doi:10.1007/s10784-016-9328-7 (2016).

\section{Competing interests}

The authors declare that they have no competing financial interests. 


\section{Boxes}

189

\section{Providers of genetic} resources

- Provider countries that export genetic resources

- Typically biodiversity-rich countries located in the Global South

- Often low-income countries

\section{Users of genetic resources}

- Import genetic resources

- Companies and research institutions localised in "user countries"

- User countries are typically affluent industrialized countries located in the Global North 


\section{Box 2}

Observations and experience indicating that the NP may hinder research collaboration

Concerns about a negative effect of the NP on research collaboration are based on author's indication or evidence:

A) Personal experience with past negative effects of ABS regulation or present uncertainty may cause hesitation to enter future collaborations.

- Evidence 1: Past experience with a project assessing effects of naturally low phosphorus levels in soils. Originally experiments were planned in Colombia. However, due to overly restrictive legislation and difficulties to export samples, the project was moved to Madagascar, where less restrictive rules apply.

- Evidence 2: Past experience involving a three year funded collaboration with researchers in India. Administrative issues including ABS negotiations took so long that samples were finally shipped one year before the project ended.

- Evidence 3: Current experience involving exchange of environmental DNA (eDNA) in a collaboration with Thai researchers. It is not clear whether eDNA qualifies as genetic resource in this context and may therefore be subject to ABS as outlined in the NP.

B) Various observations support concerns about increasing hesitation to enter research collaborations.

- Evidence 4: Some collaboration started from requests for sample analysis by researchers in low-income countries with little access to rapidly evolving and expensive analytical infrastructure. We observe an increased hesitation to accept such requests since the NP has entered into force, because it remains uncertain what kind of permissions are required to exchange samples across borders.

- Evidence 5: Observation of a general trend to work with samples already archived in existing collections or to stick to ongoing collaborations with countries that have well-established and efficient NP administrative processes.

- Evidence 6: A survey amongst Malaysian researchers indicated that in less affluent countries there are also scientists who expect a negative impact from ABS regulations on scientific collaboration ${ }^{15}$. 


\section{Box 3}

Measures to prevent the Nagoya Protocol (NP) from backfiring on the Global South

Measures to prevent the NP from backfiring on the Global South can be implemented at different levels. Suggestions for governments, scientific institutions and researchers in typical provider and user countries (as outlined in Box 1) are listed below.

\begin{tabular}{|c|c|c|}
\hline & $\begin{array}{l}\text { Different actors in provider } \\
\text { countries }\end{array}$ & Different actors in user countries \\
\hline 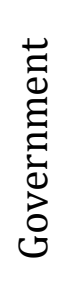 & $\begin{array}{l}\text { - Introduce simplified procedures for non- } \\
\text { commercial research in the domestic ABS } \\
\text { legislation, e.g. referring to article 8a of the } \\
\text { NP. } \\
\text { Provide transparent and efficient procedures } \\
\text { to deal with requests for access to genetic } \\
\text { resources. }\end{array}$ & $\begin{array}{l}\text { - Provide information about the NP and its } \\
\text { implication to researchers, and advise on how } \\
\text { to implement ABS procedures. } \\
\text { - Provide a (funded) framework in which } \\
\text { research institutions can support scientists } \\
\text { during ABS negotiations. }\end{array}$ \\
\hline 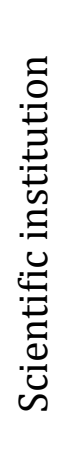 & $\begin{array}{l}\text { - Provide education introducing key elements } \\
\text { and procedures of the NP to optimally } \\
\text { prepare international collaborations. } \\
\text { - Provide education on and awareness for the } \\
\text { particular challenges of trans-boundary } \\
\text { research-collaborations. } \\
\text { - Support scientists in international research } \\
\text { collaborations. }\end{array}$ & $\begin{array}{l}\text { - Provide education introducing key elements } \\
\text { and procedures of the NP, and fostering } \\
\text { understanding of the situation in provider } \\
\text { countries, including the reasoning why the NP } \\
\text { has been developed. } \\
\text { - Provide education on and awareness for the } \\
\text { particular challenges of trans-boundary } \\
\text { research-collaborations. } \\
\text { - Support scientists in international research } \\
\text { collaborations, including a helpdesk and legal } \\
\text { support for setting up ABS procedures. }\end{array}$ \\
\hline 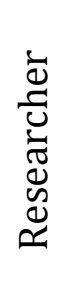 & $\begin{array}{l}\text { - Consider differences in interests and } \\
\text { requirements between collaboration } \\
\text { partners. } \\
\text { - Be aware of the challenge the NP may present } \\
\text { for collaborators in user countries. } \\
\text { - Support collaborators in user countries with } \\
\text { procedures in provider countries. }\end{array}$ & $\begin{array}{l}\text { - Consider differences in interests and } \\
\text { requirements between collaboration } \\
\text { partners. } \\
\text { - Be aware of the NP and its requests. } \\
\text { - Remain open for new research collaborations } \\
\text { also in cases that involve exchange of } \\
\text { biological material. }\end{array}$ \\
\hline
\end{tabular}

